\title{
At what age do bronchodilator drugs work?
}

\author{
W. LENNEY AND A. D. MILNER \\ From the Department of Child Health, University Hospital and Medical School, Nottingham
}

SUMMARY Using a modification of the forced oscillation technique we have measured respiratory resistance before and after nebulised salbutamol therapy in 32 wheezing children aged 7 months to 3 years 7 months. 12 of the children were also studied in a total body plethysmograph. No child under 18 months of age showed a greater than $5 \%$ fall in resistance or any fall in thoracic gas volume. In contrast, 18 of 20 children over 20 months of age showed a fall in resistance greater than $20 \%$.

Williams and McNicol (1969) could not separate younger children with wheezy bronchitis and recurrent wheezing episodes from their elder asthmatic counterparts and considered them to be part of the spectrum of asthma. Despite this, the treatment of wheezing in children under 5 years of age is inconsistent, and antibiotics are frequently used when bronchodilator therapy would be more appropriate if bronchospasm is the predominant abnormality.

In a recent study (Lenney and Milner, 1978) we performed lung function tests before and after exercise in 23 children aged $3 \cdot 1$ to $5 \cdot 2$ years with recurrent wheezing episodes. 20 of these children showed abnormal postexercise bronchoconstriction compared with a group of normal controls, and all 23 children responded to inhalation of nebulised salbutamol solution by showing a rise in peak expiratory flow rate and a fall in total respiratory resistance $\left(R_{T}\right)$, mimicking the physiological responses of the older asthmatic child. In contrast, however, Radford (1975), Phelan and Williams (1969), and Rutter et al. (1975) showed no improvement in lung function after salbutamol inhalation in wheezy children under one year of age. The aim of this study was to identify when between the ages of 12 months and 3 years nebulised salbutamol becomes an effective therapeutic agent in children with recurrent wheezing attacks.

\section{Theory}

Total respiratory resistance $\left(R_{T}\right)$ was measured using a modification of the forced oscillation technique (DuBois et al., 1956a; Cogswell, 1973). This technique depends on the fact that when an

Received 8 November 1977 oscillating sine-wave airflow is applied to the respiratory tract, the transthoracic pressure changes induced are related to the total impedance of the system. The total impedance comprises $R_{r}$, elastic impedance, and inertial impedance. At six cycles per second, the resonant frequency of the respiratory system, elastic and inertial impedance are of equal magnitude and opposite in sign, therefore cancelling out and allowing $R_{\mathrm{T}}$ to be calculated directly.

The apparatus used was similar to that of Rutter et al. (1975) (Fig. 1). The flow oscillations were generated by a sine-wave generator and fed to a rigid cone loud-speaker mounted inside a wooden box. These oscillations were conducted to a softflanged face mask by a $3 \mathrm{~cm}$-bore tube. Rebreathing was prevented by feeding a $41 / \mathrm{min}$ bias flow of air into the face mask. This emerged from the system via a small leak in the box. Flow was measured with a Fleisch pneumotachograph type 1 . The pressure drop across the pneumotachograph and the mouth pressure changes were measured by identical differential pressure transducers (Elema Schönander EMT 32C). The signals were fed through an amplification system (SE Laboratories EMMA) to a 6-inch ultraviolet recorder (SE Laboratories Oscillograph 3006). We modified the flow signal by incorporating an active bypass filter which effectively eliminated frequencies below 2 cycles per second, hence eliminating the child's own breathing pattern. The resulting flow trace was easy to read and made calculations of $\mathbf{R}_{\mathrm{T}}$ more accurate (Fig. 2). At the end of each study, mouth pressure was calibrated using a water manometer and air flow using a rotameter. $\mathbf{R}_{\mathrm{T}}$ was calculated at the midexpiratory point by dividing the mouth pressure oscillation by the flow oscillation.

The children over $2 \frac{3}{4}$ years were able to use the machine well and required no sedation. They sat on 


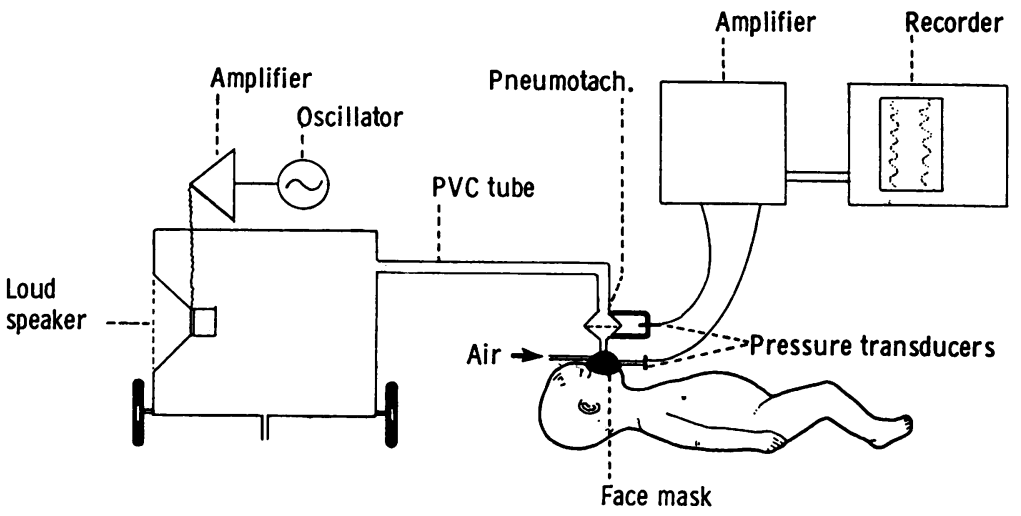

Fig. 1 Schematic representation of the apparatus.
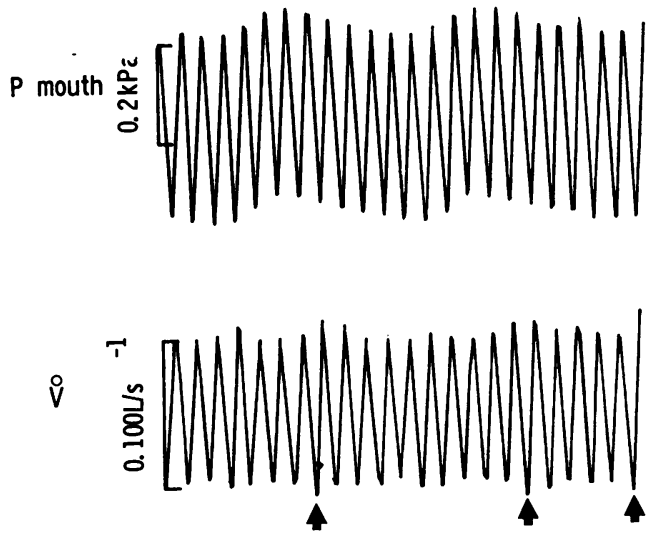

Fig. 2 Trace of mouth pressure (P mouth) and mouth flow $(\dot{V})$ during measurement of total respiratory resistance using the forced oscillation technique. The slow oscillations on the mouth pressure trace are produced by the child's tidal breathing (inspiration producing an upward deflection). This has been eliminated on the flow trace by the active bypass filter except at the end tidal points when the tidal flow produces artefacts (arrows). The rapid oscillations $(6 \mathrm{~Hz})$ are produced by the loud-speaker.

a chair and breathed quietly through a mouthpiece which replaced the face mask (Lenney and Milner, 1978).

Airways resistance (RAw) and thoracic gas volume (TGV) were measured in 12 children using a modification of the plethysmographic technique (Radford, 1974). The plethysmograph was a specially constructed perspex box of 250 litres capacity. Measurements were made with the child in the supine position. A servo controlled heating system was incorporated to maintain the whole of the shutter system, rebreathing bag, and face mask at $36^{\circ} \mathrm{C}$ (Stocks et al., 1977). Plethysmograph pressure, mouth pressure, and air flow signals were obtained, amplified, and simultaneously relayed to both axes of a cathode ray storage oscilloscope from which direct readings were taken and calculated using standard techniques (DuBois et al., 1956b, c).

Each child was given $80 \mathrm{mg} / \mathrm{kg}$ chloral hydrate as sedation. When sleeping, the child was placed supine on a couch and the face mask was slowly lowered over the mouth and nose using gentle pressure until an airtight seal was obtained. Traces were obtained over five or six consecutive breaths. The $\mathbf{R}_{\mathbf{T}}$ was expressed as the mean of at least six readings. Repeat measurements were obtained at 5 minutes. 12 of the children were then placed in the body plethysmograph to obtain RAW and TGV values. Each child was then given $0.5 \mathrm{ml}$ salbutamol respirator solution dissolved in $1.5 \mathrm{ml}$ sterile water through a Pari nebuliser. $\mathbf{R}_{\mathrm{T}}$ measurements were made at 10 minutes after therapy. RAw and TGV measurements were also repeated in the 12 children. Pulse rate was recorded before and after therapy.

The reproducibility of the forced oscillation technique was assessed by comparing the two readings before giving salbutamol. The coefficient of variation of the percentage difference between the two pre-salbutamol $R_{T}$ values was $8 \cdot 9 \%$.

\section{Subjects}

Thirty-two patients ( 22 boys, 10 girls) were studied on 34 occasions. Their ages at the time of study ranged from 7 months to 3 years 7 months (mean 23 months). They were all recovering from an acute wheezing episode and although well at the time of testing, they still had increased respiratory efforts with prolonged expiration and an audible expiratory wheeze. All but one had had at least two previous wheezing episodes. 9 had a history of eczema and 20 had a family history of asthma. The 12 children 
studied in the total body plethysmograph had a mean age of 21 months (range 9 months to 2 years 8 months).

\section{Results}

As there are no normal data available for $\mathbf{R}_{\mathrm{T}}$ over the age range studied and no data published on RAW using a heated shutter system, all results have been expressed as a percentage change from the initial reading. After medication no child under 18 months of age showed a fall in $R_{T}$ greater than $5 \%$, whereas all but one over 20 months showed a fall in $R_{r}$. greater than $15 \%$ (Fig. 3). As all children were wheezing and had audible expiratory rhonchi at the time of testing, we had no doubt that all had airways obstruction.

The RAw measurements obtained using the total body plethysmograph confirmed the findings provided by the oscillation technique, never falling by more than $10 \%$ in the 3 children tested under 18 months of age, but falling by more than $18 \%$ in 6 of the 7 children over the age of 20 months after the inhalation of nebulised salbutamol (Fig. 4).

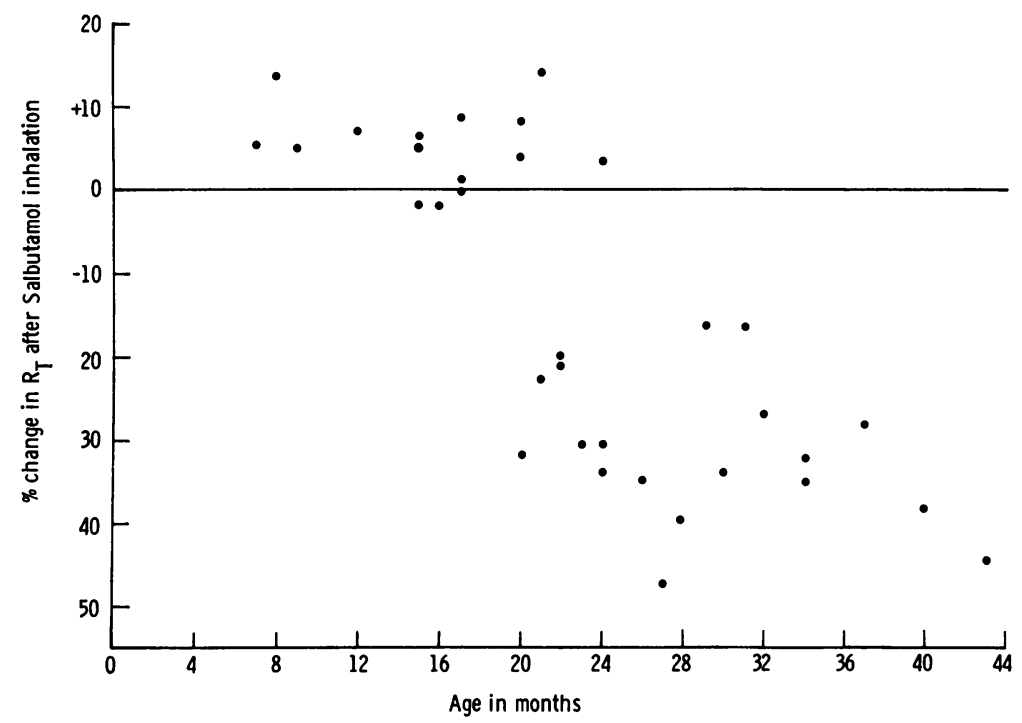

Fig. 3 Total respiratory resistance measurements on 34 occasions in 32 children whose ages range from 7 months to 3 years 7 months. Each $\bullet$ represents the percentage change in total respiratory resistance from the initial reading to the reading taken 10 minutes after the inhalation of nebulised salbutamol.

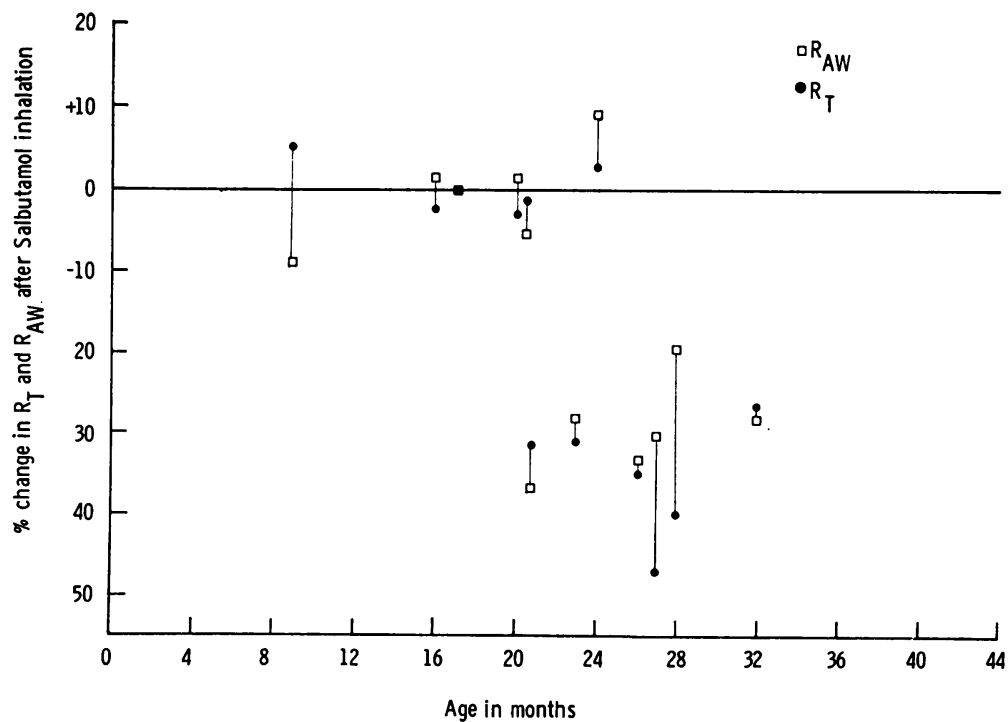

Fig. 4 Comparison of total respiratory resistance $\left(R_{T}\right)$ and airways resistance ( $R A W)$ measurements expressed as a percentage change from the initial reading to the reading taken after the inhalation of nebulised salbutamol in 12 wheezy children. 
Only one child had a TGV below the predicted value for height (Doershuk et al., 1970). On average TGV was $44 \%$ above the predicted level with a range of $-15 \%$ to $+82 \%$. Only 2 of the 12 children, aged 1 year 11 months and 2 years 4 months, showed a fall in TGV after salbutamol therapy, of $12 \%$ and $17 \cdot 7 \%$ respectively.

Under 18 months of age, 7 of the 11 children showed a small increase in $R_{T}$ after salbutamol therapy, but these findings were not supported by the plethysmograph data and were not significant. One child who did not respond to salbutamol at the age of 17 months had a $40 \%$ fall in $R_{T}$ when retested at the age of 28 months. One other child responded at ages of 22 months and 23 months with a fall in $R_{T}$ of $20 \%$ and $31 \%$ respectively. Mean initial pulse rate was 116 per minute. Mean pulse rate 5 minutes after salbutamol therapy was 140 per minute. An increase in pulse rate was seen in all the children.

\section{Discussion}

These results show that children over the age of 20 months with recurrent wheezing attacks respond to nebulised salbutamol in a similar manner to their older asthmatic counterparts. We were however unable to show any improvement in lung function or clinical state in the wheezy children between the ages of 7 and 18 months of age. Consistent increase in pulse rate after salbutamol inhalation suggested that significant amounts of the drug were being absorbed, sufficient to show some bronchodilator effect. Why children under 18 months of age with recurrent wheezing attacks fail to respond to bronchodilator therapy remains obscure. One possible explanation is that we were studying different pathologies in the different age groups, the younger children having 'bronchitis' and the older children having 'asthma'. But this is unlikely because apart from the response to salbutamol, the disease process was clinically identical in both age groups and one child who did not respond at 17 months of age obtained considerable relief of airways obstruction after salbutamol inhalation at 28 months of age.

A further possibility is that the salbutamol was leading to a fall in TGV associated with an improvement in clinical state without any change in resistance (Woolcock and Read, 1966). In none of the 12 children in whom TGV was measured was this phenomenon seen. Other explanations for failure of salbutamol therapy in children of under 18 months have been that it is related to poor development of bronchial muscle (Engel, 1962; Phelan and Williams, 1969), or that in children with narrow airways the bronchial obstruction is predominantly due to thick mucus secretions and mucosal oedema.
We conclude that (1) nebulised salbutamol solution is effective in reducing airways obstruction in most wheezing children over 20 months of age; (2) salbutamol therapy is unlikely to be of benefit when given to children under 18 months of age.

We gratefully acknowledge financial support from the Chest and Heart Foundation and from Allen and Hanburys Research Limited.

\section{References}

Cogswell, J. J. (1973). Forced oscillation technique for determination of resistance to breathing in children. Archives of Disease in Childhood, 48, 259-266.

Doershuk, C. F., Downs, T. D., Matthews, L. W., and Lough, M. D. (1970). A method for ventilatory measurements in subjects 1 month-5 years of age: normal results and observations in disease. Pediatric Research, 4, 165-174.

DuBois, A. B., Botelho, S. Y., Bedell, G. N., Marshall, R., and Comroe, J. H., Jr (1956b). A rapid plethysmographic method for measuring thoracic gas volume. Journal of Clinical Investigation, 35, 322-326.

DuBois, A. B., Botelho, S. Y., and Comroe, J. H., Jr (1956c). A new method for measuring airway resistance in man using a body plethysmograph: values in normal subjects and in patients with respiratory disease. Journal of Clinical Investigation, 35, 327-335.

DuBois, A. B., Brody, A. W., Lewis, D. H., and Burgess, B. F., Jr (1956a). Oscillation mechanics of lung and chest in man. Journal of Applied Physiology, 8, 587-594.

Engel, S. (1962). Lung Structure, p. 26. Thomas: Springfield.

Lenney, W., and Milner, A. D. (1978). Recurrent wheezing in the preschool child. Archives of Disease in Childhood, 53, 468-473.

Phelan, P. D., and Williams, H. E. (1969). Studies of respiratory function in infants with recurrent asthmatic bronchitis. Australian Paediatric Journal, 5, 187-196.

Radford, M. (1974). Measurement of airway resistance and thoracic gas volume in infancy. Archives of Disease in Childhood, 49, 611-615.

Radford, M. (1975). Effect of salbutamol in infants with wheezy bronchitis. Archives of Disease in Childhood, 50, 535-538.

Rutter, N., Milner, A. D., and Hiller, E. J. (1975). Effect of bronchodilators on respiratory resistance in infants and young children with bronchiolitis and wheezy bronchitis. Archives of Disease in Childhood, 50, 719-722.

Stocks, J., Levy, N. M., and Godfrey, S. (1977). A new apparatus for the accurate measurement of airway resistance in infancy. Journal of Applied Physiology, 43, 155-159.

Williams, H. E., and McNicol, K. N. (1969). Prevalence, natural history and relationship of wheezy bronchitis and asthma in children. An epidemiological study. British Medical Journal, 4, 321-325.

Woolcock, A. J., and Read, J. (1966). Lung volumes in exacerbations of asthma. American Journal of Medicine, 41, 259-273.

Correspondence to Dr A. D. Milner, Department of Child Health, University Hospital and Medical School, Clifton Boulevard, Nottingham NG7 2UH. 